\title{
Tryptophan concentration is the main mediator of the capacity of adipose mesenchymal stromal cells to inhibit $\mathbf{T}$-lymphocyte proliferation in vitro
}

\author{
RAMÓN MENTA $^{1, *}$, PABLO MANCHEÑO-CORVO ${ }^{1, *}$, BORJA DEL RÍO $^{1}$, \\ CRISTINA RAMÍREZ ${ }^{1}$, OLGA DELAROSA ${ }^{1}$, WILFRIED DALEMANS ${ }^{2}$ \& \\ ELEUTERIO LOMBARDO ${ }^{1}$
}

${ }^{1}$ TiGenix SAU, Parque Tecnológico de Madrid, Madrid, Spain, and ${ }^{2}$ TiGenix NV, Leuven, Belgium

\begin{abstract}
Background aims. Mesenchymal stromal cells (MSCs) have immunomodulatory properties that are mediated by cell-to-cell interactions and paracrine effects through soluble factors, among which tryptophan (Trp) conversion into kynurenine (Kyn) through the enzymatic activity of indoleamine 2,3-dioxygenase has been proven to be of special relevance. However, the respective role of Trp depletion and/or Kyn accumulation on the inhibition of T-cell proliferation by MSCs remains unclear. Methods. The effect of supplementation with increasing concentrations of Trp on the capacity of MSCs to inhibit Tlymphocyte proliferation in vitro was investigated. Results. We report that Trp supplementation impairs the capacity of adipose mesenchymal stromal cells (ASCs) to inhibit T-cell proliferation, despite the accumulation of very high concentrations of Kyn in the medium ( $>200 \mu \mathrm{mol} / \mathrm{L}$ ). Moreover, Trp supplementation after $72 \mathrm{~h}$ of peripheral blood mononuclear cell:ASC co-culture, once the inhibitory effect of ASCs was established, reverted ASC inhibition and restored T-cell proliferation. Addition to stimulated lymphocytes of Kyn inhibited T proliferation in 3 of 10 peripheral blood mononuclear cell donors, but at different concentrations, suggesting that sensitivity of lymphocytes to Kyn might be donor-dependent. Conclusions. Our results confirm the relevance of Trp metabolism as a key mediator of the immunomodulatory properties of ASCs and clarify the respective roles of the Trp/Kyn balance.
\end{abstract}

Key Words: adipose, immunosuppression, mesenchymal stromal cells, tryptophan metabolism

\section{Introduction}

Interest in using adult mesenchymal stromal cells (MSCs) to treat inflammatory diseases has grown enormously in recent years, on the basis of their capacity to modulate the function of the majority of immune cells $[1-7]$. MSCs can be isolated from several adult tissues, including bone marrow (BM-MSCs) or adipose tissue (ASCs) $[8,9]$. The immunomodulatory properties of MSCs rely not only on cell-to-cell interactions $[10,11]$ but also on effects mediated by soluble factors such as prostaglandin-E2 (PGE-2), interleukin (IL)-10 or human leukocyte antigen (HLA)-G5 [12]. Importantly, indirect paracrine effects by regulating tryptophan metabolism through the enzymatic activity of indoleamine 2,3-dioxygenase (IDO) have been proven to be of special relevance for the immunomodulatory properties of MSCs isolated from human, monkey and pig [13-15]. MSCs show such immunomodulatory properties in response to inflammatory mediators released from activated immune cells, such as interferon (IFN)- $\gamma, \mathrm{IL}-1 \beta$ and tumor necrosis factor (TNF)- $\alpha[16,17]$.

IDO is a cytoplasmic enzyme that participates in the catabolic metabolism of the essential amino acid tryptophan (Trp) along the kynurenine (Kyn) pathway and is known to modulate the immune system (ie, inhibit T-lymphocyte proliferation) and to induce tolerogenic responses $[18,19]$. Some of the Trp metabolites generated by IDO, such as Kyn, have been reported to suppress $\mathrm{T}$-cell proliferation, induce apoptosis, and generate regulatory $\mathrm{T}$ cells [20-25]. Furthermore, Trp deprivation leads to blockage of the translation of most transcripts, which results in the inhibition of T-effector cells $[26,27]$.

*These authors contributed equally to this work.

Correspondence: Eleuterio Lombardo, TiGenix SAU, Parque Tecnológico de Madrid, C/ Marconi 1, 28760, Tres Cantos, Madrid, Spain. E-mail: eleuterio. lombardo@tigenix.com 
IDO has also been reported to act as a tolerogenic intracellular signaling molecule in plasmacytoid dendritic cells through protein-protein interactions independent of its enzymatic activity [28]. The expression of IDO is tightly regulated by exogenous signals, and most cells do not constitutively express the protein. Thus, IDO is not expressed in resting MSCs, but it is induced by activation through proinflammatory mediators and cytokines, mainly IFN$\gamma[29,30]$. In response to IFN- $\gamma$, MSCs express IDO and as a result, Trp concentration rapidly declines in the surrounding environment with the concomitant accumulation of Kyn. Neighboring cells may then respond to limited access to Trp and/or accumulation of Kyn, and, as a consequence, concurrent lymphocyte proliferation is inhibited $[13,15]$.

We have previously reported that blockage of IDO activity almost completely abolished the capacity of ASCs to inhibit lymphocyte proliferation in vitro [29]. In this study, we sought to clarify the respective roles of Trp depletion and/or Kyn accumulation on the inhibition of $\mathrm{T}$-cell proliferation by ASCs in vitro because the relative contribution of each arm of this Trp/Kyn balance on the immunomodulatory capacity of ASCs has not been studied in detail. Our results show that Trp supplementation impairs the capacity of ASCs to inhibit T-cell proliferation, despite the accumulation of very high concentrations of Kyn in the medium. Moreover, Trp supplementation, once the inhibitory effect of ASCs was established, could restore T-cell proliferation.

\section{Methods}

\section{Isolation and cell culture}

Human adipose tissue aspirates from healthy donors were washed twice with phosphate-buffered saline and digested with $0.075 \%$ collagenase (Type I, Invitrogen, Carlsbad, CA, USA). The digested sample was washed with $10 \%$ fetal bovine serum (FBS), treated with $160 \mathrm{mmol} / \mathrm{L} \mathrm{NH}_{4} \mathrm{Cl}$ to eliminate remaining erythrocytes and suspended in culture medium (Dulbecco's modified Eagle's medium; DMEM) with $10 \%$ FBS. Cells were seeded $\left(2-3 \times 10^{4} \mathrm{cells} / \mathrm{cm}^{2}\right)$ in tissue culture flasks and expanded $\left(37^{\circ} \mathrm{C}, 5 \% \mathrm{CO}_{2}\right)$ with change of culture medium every 3-4 days. Cells were transferred to a new flask $\left(10^{3}\right.$ cells $\left./ \mathrm{cm}^{2}\right)$ when they reached $90 \%$ confluence. Experiments were performed with cells from 2 male and 2 female adult donors at population doublings (PD) 12-14. ASCs were defined according to the criteria of the International Society for Cellular Therapy [31]: being positive for HLA-I, CD73, CD90 and CD105 and negative for CD11b, CD14, CD31, CD34 and CD45 and by their capacity to differentiate to adipocytes, chondrocytes or osteocytes. ASCs at low PDs showed higher differentiation capacity compared with PD12-14. Peripheral blood mononuclear cells (PBMC) were isolated from buffy coats with the use of Ficoll-Paque Plus (GE Healthcare Biosciences $A B$, Uppsala, Sweden), following the supplier's protocol. Briefly, blood samples were diluted with balanced salt solution and Ficoll was added to create a density gradient. After centrifugation, we gently collected the interface containing mononuclear cells. Purity was verified by flow cytometry. Buffy coats were provided by the National Transfusion Centre of the Comunidad Autónoma of Madrid, Spain.

\section{Reagents and antibodies}

5(6)-Carboxyfluorescein diacetate $N$-succinimidyl ester (CFSE), L-Tryptophan and L-Kynurenine were from Sigma-Aldrich (St Louis, MO, USA). The Pan T-cell Activation kit (anti-CD3, CD2, CD28-coated beads) was from Milteny Biotech (Bergisch Gladbach, Germany). Anti-CD3, CD4 and CD8 antibodies and 7-amino-actinomycin D (7-AAD) were from Becton Dickinson (San Diego, CA, USA). Antihuman IFN- $\gamma$ and isotype control were from Invitrogen. Anti-IDO-phycoerythrin antibody was from eBioscience (San Diego, CA, USA).

\section{IDO activity}

IDO activity was measured by determining both Trp and Kyn concentrations on conditioned supernatants at different time points. A total of $100 \mu \mathrm{L}$ of conditioned supernatants were mixed with $100 \mu \mathrm{L}$ of buffer phosphate $50 \mathrm{mmol} / \mathrm{L}$ and $25 \mu \mathrm{L}$ of $2 \mathrm{~mol} / \mathrm{L}$ trichloroacetic acid. Supernatants were centrifuged at $15,600 \mathrm{~g}$ for 10 min and $100 \mu \mathrm{L}$ were collected and analyzed by highperformance liquid chromatography (HPLC) (717plus Autosampler; Waters, Milford, MA, USA).

\section{IDO expression}

PBMCs activated with anti-CD3, CD2, CD28-coated beads were cultured with ASCs in 6-well-plates with the use of a transwell system with a $0.4-\mu \mathrm{m}$ pore size membrane (Corning Costar, Schiphol-Rijk, the Netherlands) to allow exchange of soluble factors but separation of both cell types, keeping the 1:25 ASC:PBMC ratio. At the indicated time points, ASCs were harvested and intracellularly stained with antiIDO antibody with the use of the kit for intracellular staining from eBioscience, following the manufacturer's instructions. A total of $10 \times 10^{3}$ events were acquired through the use of a FACScalibur (BD Bioscience). CellQuest-pro software was used for acquisition and analysis. CaliBRITE beads (BD Bioscience) were used before each assay to calibrate the cytometer. 


\section{Neutralization experiments}

PBMCs were stimulated with anti-CD3, CD2, CD28-coated beads for $24 \mathrm{~h}$ and the conditioned supernatant was collected, spun down to remove cells and incubated for $1 \mathrm{~h}$ at room temperature with either a neutralizing anti-human IFN- $\gamma$ antibody or control $(10 \mu \mathrm{g} / \mathrm{mL}$ each). ASCs were then cultured with these supernatants for $24 \mathrm{~h}$ and $48 \mathrm{~h}$, and IDO activity was measured by means of HPLC.

\section{Immunosuppression assay}

For CFSE labeling, PBMCs were washed extensively to remove FBS, resuspended in a 10- $\mu \mathrm{mol} / \mathrm{L}$ CFSE solution (10 7 PBMCs per $200 \mu \mathrm{L}$ of solution), and incubated with constant shaking $\left(37^{\circ} \mathrm{C}, 10 \mathrm{~min}\right)$. Reaction was stopped with cold Roswell Park Memorial Institute media (RPMI) $+10 \%$ FBS. Cells were washed and cultured overnight, and 1 aliquot was used to set up and control FL-1 voltage for CFSE in the cytometer. After overnight resting, CFSE-labeled PBMCs were activated with the Pan T Cell Activation Kit (microbeads coated with anti-CD3, -CD2 and -CD28; Miltenyi Biotech, Auburn, CA, USA) following the manufacturer's instructions, or were left unstimulated. PBMCs $\left(10^{6}\right.$ cells/ well) were cultured in 24-well plates alone or with overnight seeded ASCs $\left(4 \times 10^{4}\right.$ cells/well; ASC:PBMC ratio, $1: 25)$ in a total volume of $1 \mathrm{~mL}$ of $\mathrm{RPMI}+10 \%$ FBS and increasing concentrations of $\operatorname{Trp}(+54 \mu \mathrm{mol} /$ $\mathrm{L},+100 \mu \mathrm{mol} / \mathrm{L},+200 \mu \mathrm{mol} / \mathrm{L}$ ) were added. The $1: 25$ ratio was chosen because it provided a high inhibitory effect, on the basis of our previous studies [29]. At the indicated time points, PBMCs were harvested and labeled with 7-AAD and anti-CD3 antibody (CD4 or CD8 when indicated), and cell proliferation of the CD3pos/7-AADneg population (viable CD3 T lymphocytes) was determined by flow cytometry, according to loss of CFSE signal. When indicated, Trp was supplemented after $72 \mathrm{~h}$ of co-culture of PBMCs and ASCs, and proliferation was determined at $120 \mathrm{~h}$.

For experiments of reversibility of inhibitory effect of ASCs, stimulated CFSE-PBMCs that were in culture with ASCs for $120 \mathrm{~h}$ were spun down $(400 g, 5$ $\mathrm{min})$, resuspended in fresh medium $\left(10^{6}\right.$ cells $\left./ \mathrm{mL}\right)$ and re-stimulated as mentioned above in the absence of ASCs. Proliferation was determined after 96 h. Data were analyzed with the use of FCSExpress 4 software (De Novo Software, Glendale, CA, USA). CaliBRITE beads (BD Bioscience, Erembodegem-Aalst, Belgium) were used before each assay to calibrate the cytometer.

\section{Proliferation of PBMCs in the presence of Kyn}

CFSE-labeled PBMCs were stimulated in the absence or presence of increasing concentrations of
Kyn $(10,20,30,50$ and $100 \mu \mathrm{mol} / \mathrm{L})$, and proliferation was determined at $120 \mathrm{~h}$ by means of flow cytometry as indicated above.

\section{Enzyme-linked immunoassay}

Concentrations of IL-10, PGE-2 and HLA-G in conditioned supernatants were determined by means of enzyme-linked immunoassay (ELISA) at different time points, following the manufacturer's instructions. ELISA for IL-10 was from Human IL-10 Affymetrix-eBioscience (San Diego, CA, USA). ELISA for sHLA-G (detecting HLA-G1/5) was from Biovendor Research and Diagnostic Products (Brno, Czech Republic) and ELISA for PGE-2 was from Thermo Scientific (Rockford, IL, USA).

\section{MTT assay}

The effect of Trp supplementation on ASC growth was assessed by means of the CellTiter AQueous One Solution Cell Proliferation Assay (Promega, Madison, WI, USA). Briefly, ASCs were seeded in a $96-w e l l$ plate $\left(3 \times 10^{3}\right.$ cells/well $)$ and cultured for 7 days in the absence or presence of increasing concentrations of $\operatorname{Trp}(+54 \mu \mathrm{mol} / \mathrm{L},+100 \mu \mathrm{mol} /$ $\mathrm{L},+200 \mu \mathrm{mol} / \mathrm{L}$ ). Absorbance (optical density, 492 $\mathrm{nm}$ ) was measured in an ELISA reader at day 0 and day 7. Experiments were performed with the use of ASCs from 4 donors and triplicates included for each condition.

\section{Results}

IDO is induced in ASCs co-cultured with stimulated PBMCs in response to $I F N-\gamma$

We first studied whether IDO is induced in ASCs cocultured with stimulated PBMCs. Thus, CFSElabeled PBMCs were left unstimulated or stimulated with microbeads coated with anti-CD3/CD2/CD28 antibodies. Stimulated PBMCs were either cultured alone or co-cultured with ASCs (ratio ASCs:PBMCs, 1:25) separated in a transwell to allow separation of both cell types. After $24 \mathrm{~h}$, co-cultured PBMCs and ASCs were harvested and cultured independently in fresh medium for an additional $48 \mathrm{~h}$. Trp and Kyn concentrations in the medium were then determined by means of HPLC. As shown in Figure 1A, at $24 \mathrm{~h}$, depletion of Trp concomitant with the accumulation of Kyn was only observed when stimulated PBMCs were cultured with ASCs. When these cells were separated and further cultured for an additional $48 \mathrm{~h}$, depletion of Trp and high accumulation of Kyn was only observed in supernatants from ASCs previously cultured with stimulated PBMCs, indicating that a 
Additional 48h
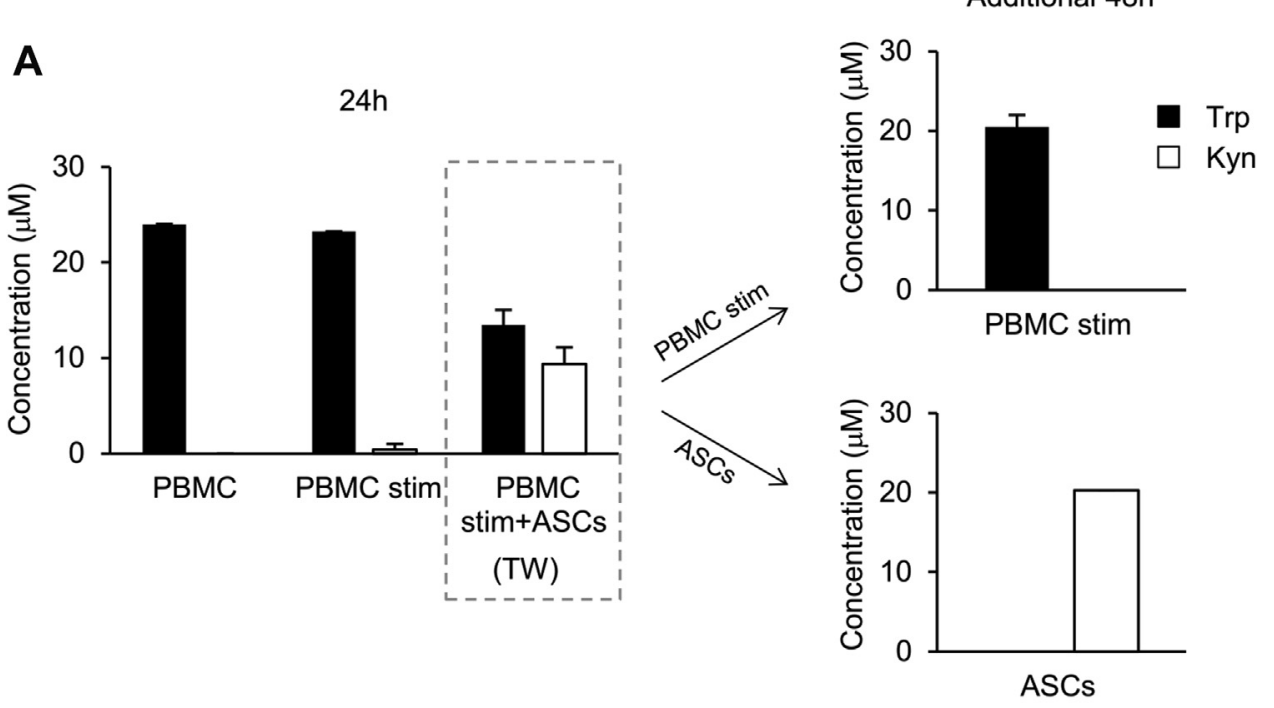

B

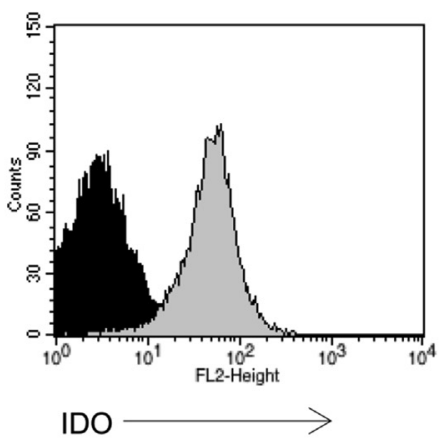

ASCs

$\square$ ASCs after co-culture with PBMC stim

C

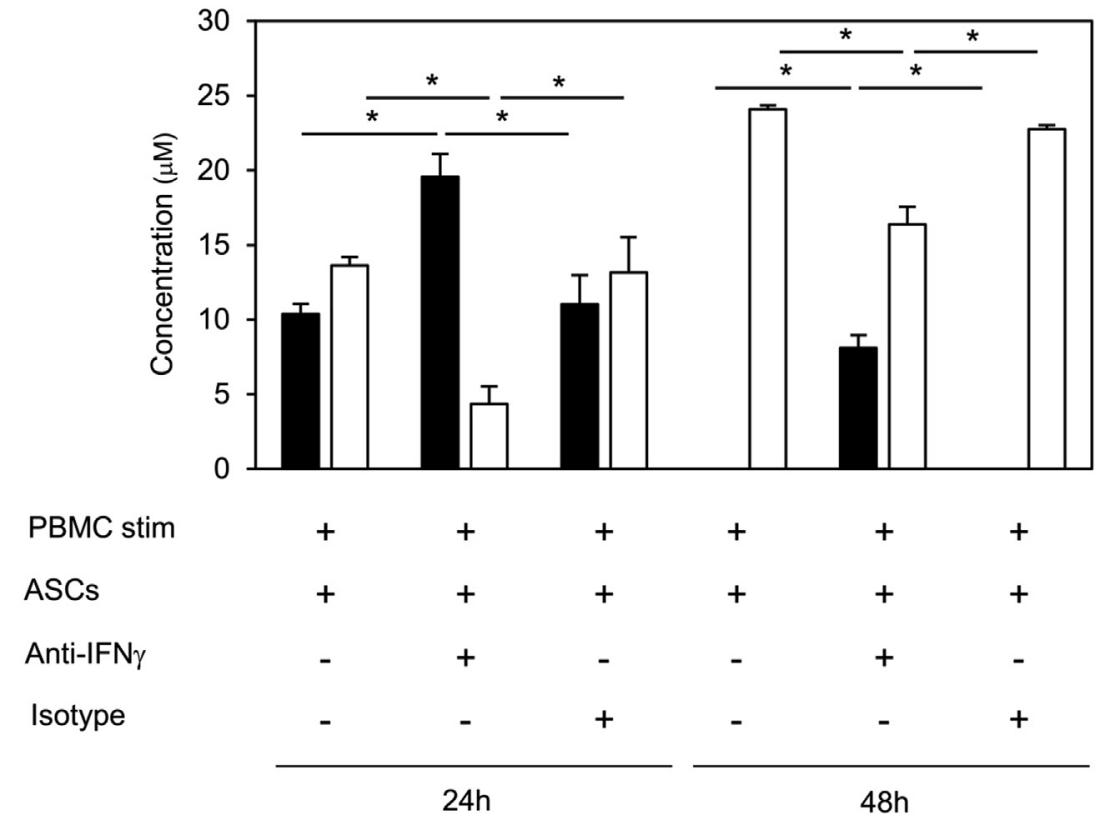

$\begin{array}{ll}\square & \text { Trp } \\ \square & \text { Kyn }\end{array}$ 
Trp catabolizing activity was induced in ASCs after culture with activated PBMCs. The expression of IDO in ASCs co-cultured with stimulated PBMCs was confirmed by means of flow cytometry with the use of a specific antibody for IDO (Figure 1B). Finally, the importance of IFN $-\gamma$ in the induction of IDO by ASCs co-cultured with stimulated PBMCs was studied with the use of a neutralizing antibody. Thus, conditioned supernatants from 24-h-stimulated PBMC were generated and incubated for $1 \mathrm{~h}$ with either a neutralizing antibody against human IFN- $\gamma$ or isotype control. ASCs were then cultured with these supernatants for $24 \mathrm{~h}$ and $48 \mathrm{~h}$, and Trp and Kyn concentrations were determined by means of HPLC. As shown in Figure 1C, whereas IFN- $\gamma$ neutralization significantly inhibited the degradation of Trp and accumulation of Kyn at both time points, the isotype control had no effect. These results show that IFN- $\gamma$ released by activated PBMCs mediates the induction of the Trp catabolizing activity of ASCs.

\section{Trp levels modulate the capacity of ASCs to inhibit T-lymphocyte proliferation in vitro}

To evaluate the importance of $\operatorname{Trp}$ catabolism in the immunosuppressive capacity of ASCs, we carried out Tcell proliferation assays in the presence or absence of ASCs (ratio ASCs:PBMCs, 1:25), in which culture medium (concentration of Trp in RPMI $+10 \%$ FBS is approximately $25 \mu \mathrm{mol} / \mathrm{L}$ ) was supplemented with 54 $\mu \mathrm{mol} / \mathrm{L}$ (to obtain a final concentration similar to that found in DMEM+10\% FBS), $100 \mu \mathrm{mol} / \mathrm{L}$ and 200 $\mu \mathrm{mol} / \mathrm{L}$ of Trp. CFSE-labeled PBMCs were stimulated with microbeads coated with anti-CD3/CD2/CD28 antibodies, and proliferation of viable CD3 $\mathrm{T}$ cells was determined at $72 \mathrm{~h}$ and $96 \mathrm{~h}$ by flow cytometry. T lymphocytes proliferated up to generations $4(\mathrm{G} 4)$ and 6 (G6) at $72 \mathrm{~h}$ and $96 \mathrm{~h}$, respectively (Figure 2A). Addition of supplementary concentrations of Trp did not affect $\mathrm{T}$-cell proliferation. When PBMCs were cultured with ASCs, T-cell proliferation was blocked at generation $2(\mathrm{G} 2)$ at both time points. However, addition of supplementary Trp impaired the inhibitory capacity of ASCs (Figure 2A). The effect appeared to be dose-dependent (the percentage of cells in G3 at $72 \mathrm{~h}$ or G4 at $96 \mathrm{~h}$ increased with the Trp supplemented) and more evident at $72 \mathrm{~h}$ than at $96 \mathrm{~h}$. Moreover, Trp supplementation affected to a similar extent the inhibitory effect of ASCs on both CD4 and CD8 T-cell subsets, indicating that $\operatorname{Trp}$ starvation, as a result of IDO activity, is a mechanism commonly implicated in the control of proliferation by ASCs of both T-cell subsets (Figure 2B).

Furthermore, we also tested whether Trp supplementation may affect the proliferation of ASCs. Thus, ASCs were cultured at increasing concentrations of Trp and proliferation was determined after 7 days by means of MTT assay. Our results indicated that Trp supplementation does not affect ASC proliferation (data not shown).

To determine the dynamics of Trp metabolism in our experimental settings, the concentration of Trp and Kyn was determined by means of HPLC in conditioned supernatants at $72 \mathrm{~h}$ and $96 \mathrm{~h}$ (Figure 3A). In unstimulated PBMCs, the concentration of Trp increased according to the added Trp at both time points (mean Trp concentration at $96 \mathrm{~h}$; no Trp added: $24.69 \mu \mathrm{mol} / \mathrm{L} ;+54 \mu \mathrm{mol} / \mathrm{L}$ added: 81.41 $\mu \mathrm{mol} / \mathrm{L} ;+100 \mu \mathrm{mol} / \mathrm{L}$ added: $128.30 \mu \mathrm{mol} / \mathrm{L} ;+200$ $\mu \mathrm{mol} / \mathrm{L}$ added: $210.81 \mu \mathrm{mol} / \mathrm{L})$. In stimulated PBMCs, the Trp concentration also increased proportionally to the added Trp, but to slightly lower levels compared with unstimulated PBMCs (mean Trp concentration at $96 \mathrm{~h}$; no Trp added: $9.13 \mu \mathrm{mol} /$ $\mathrm{L} ;+54 \mu \mathrm{mol} / \mathrm{L}$ added: $59.48 \mu \mathrm{mol} / \mathrm{L} ;+100 \mu \mathrm{mol} / \mathrm{L}$ added: $104.38 \mu \mathrm{mol} / \mathrm{L} ;+200 \mu \mathrm{mol} / \mathrm{L}$ added: 188.73 $\mu \mathrm{mol} / \mathrm{L})$. This reduction in Trp concentration, which is not concomitantly accompanied by a major accumulation of Kyn, is not due to IDO activity but to metabolic amino acid consumption on active proliferation of stimulated $\mathrm{T}$ lymphocytes. However, vast conversion of Trp into Kyn, indicative of IDO activity, was detected when activated PBMCs were cultured with ASCs. In fact, in the presence of ASCs, remaining levels of Trp were undetectable in all the conditions except when $+200 \mu \mathrm{mol} / \mathrm{L}$ of $\operatorname{Trp}$ was added (mean Trp concentration at $96 \mathrm{~h}: 4.74 \mu \mathrm{mol} / \mathrm{L}$ ), whereas Kyn highly accumulated proportionally to the concentration of added Trp (mean Kyn concentration at $96 \mathrm{~h}$; no Trp added: $23.80 \mu \mathrm{mol} /$ $\mathrm{L} ;+54 \mu \mathrm{mol} / \mathrm{L}$ added: $80.91 \mu \mathrm{mol} / \mathrm{L} ;+100 \mu \mathrm{mol} / \mathrm{L}$ added: $126.95 \mu \mathrm{mol} / \mathrm{L} ;+200 \mu \mathrm{mol} / \mathrm{L}$ added: 225.33 $\mu \mathrm{mol} / \mathrm{L}$ ) (Figure $3 \mathrm{~A}$ ). In addition, the effect of Trp

Figure 1. IFN- $\gamma$ released by stimulated PBMCs induces expression of IDO by ASCs. (A) PBMCs were stimulated with anti-CD3/CD2/ CD28-coated beads and cultured in the absence or presence of ASCs (ratio 1:25, ASCs:PBMCs) in transwell conditions for $24 \mathrm{~h}$. Stimulated PBMCs and ASCs were then separated and cultured independently in fresh medium for an additional $48 \mathrm{~h}$, and Trp and Kyn concentrations were measured by means of HPLC at the indicated time points. Mean and standard deviations of 2 experiments performed in triplicates are shown. Black bars indicate Trp; white bars: Kyn. (B) Expression of IDO in unstimulated ASCs and ASCs cultured for $24 \mathrm{~h}$ with stimulated PBMCs was determined by means of flow cytometry with the use of a monoclonal antibody against human-IDO. Black indicates unstimulated ASCs; gray, ASCs cultured with stimulated PBMC. (C) Conditioned supernatants from 24-h-stimulated PBMCs were incubated for $1 \mathrm{~h}$ with either a neutralizing antibody against human IFN- $\gamma$ or isotype control. ASCs were then cultured with these supernatants and Trp and Kyn concentrations were determined at $24 \mathrm{~h}$ and $48 \mathrm{~h}$ by means of HPLC. Means and standard deviations of 2 experiments performed in triplicates are shown. Black bars indicate Trp; white bars: Kyn. ${ }^{*} P<0.05$ (Student's $t$-test). 


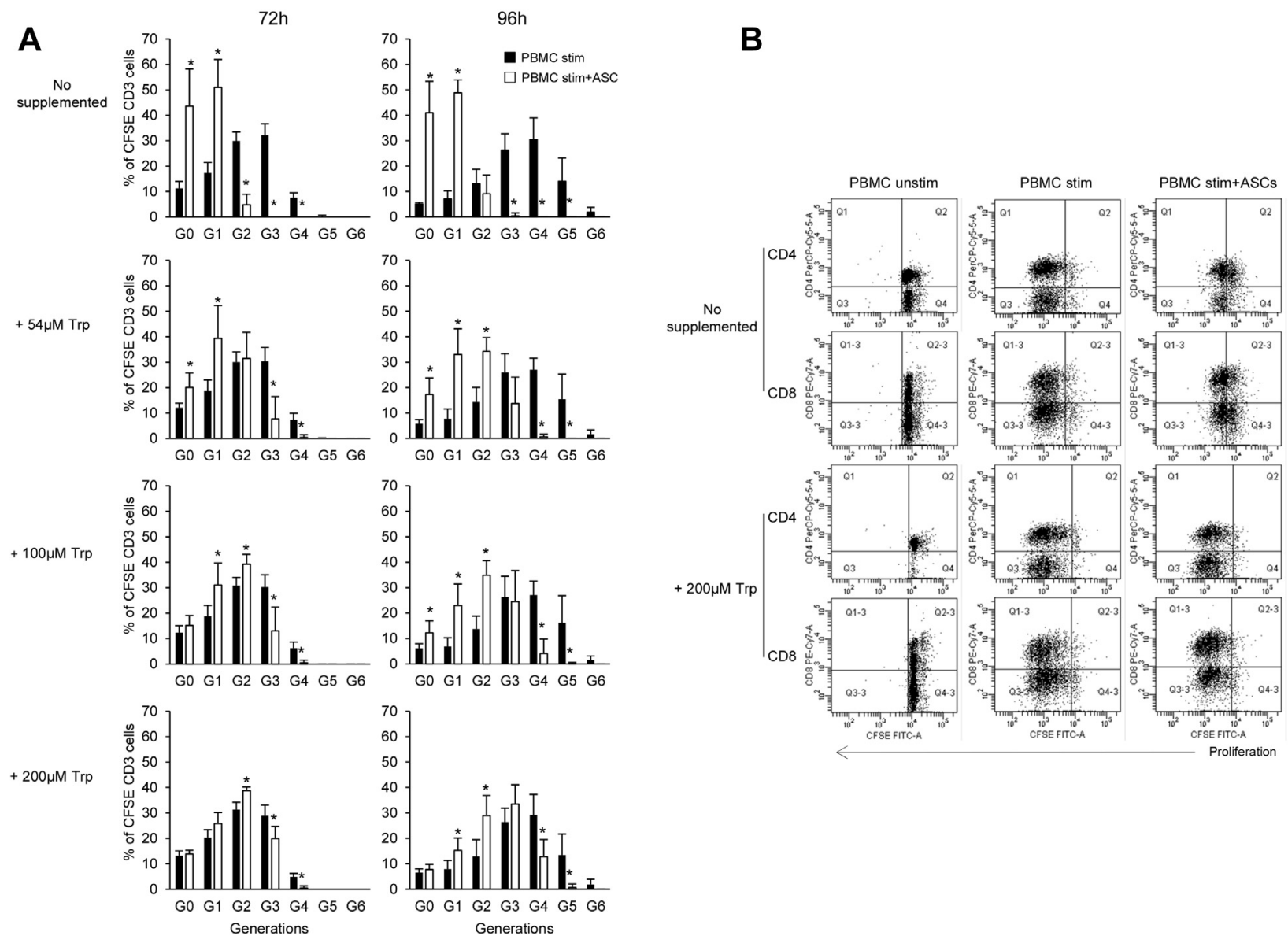

Figure 2. Trp supplementation impairs the immunomodulatory capacity of ASCs. (A) CFSE-labeled PBMCs were stimulated with antiCD3/CD2/CD28-coated beads in the absence or presence of ASCs (ratio 1:25, ASCs:PBMCs), and culture medium was supplemented with $54 \mu \mathrm{mol} / \mathrm{L}, 100 \mu \mathrm{mol} / \mathrm{L}$ or $200 \mu \mathrm{mol} / \mathrm{L}$ of Trp or left untreated. Proliferation of the viable population of CD3-positive cells (CD3pos/ 7AADneg cells) was monitored after $72 \mathrm{~h}$ and $96 \mathrm{~h}$ by means of flow cytometry, and the percentage of cells per generation was determined with the use of FCSExpress software. Means and standard deviations of the percentage of cells accumulated on each generation are shown. Black bars indicate PBMC-stimulated; white bars, PBMC-stimulated+ASCs. ${ }^{*} P<0.05$ (Student's $t$-test, PBMCstim versus PBMCstim+ASCs, for each generation). (B) Effect of Trp supplementation on the inhibitory effect of ASCs on CD4 and CD8 T subsets. After $96 \mathrm{~h}$, activated PBMCs cultured as indicated above were stained for CD4 and CD8. Plots from 1 representative experiment are shown. Experiments were performed with 4 different donors of ASCs and 2 buffy coats, in triplicates.

supplementation on the expression of IDO by ASCs was determined by means of flow cytometry after $96 \mathrm{~h}$ of co-culture. As shown in Figure 3B, IDO was similarly expressed in all the conditions, indicating that Trp supplementation had no major effect on IDO expression. Overall, these results demonstrate that supplementation of Trp impairs the capacity of ASCs to inhibit lymphocyte proliferation, despite the very high accumulation of Kyn (even above $200 \mu \mathrm{mol} / \mathrm{L}$ ).

\section{Active ASC-mediated immunosuppression of T lymphocytes is reversed by subsequent addition of Trp}

To investigate whether Trp addition could reverse the inhibitory effect of ASCs on T-cell proliferation once established, we first studied whether inhibition of T-lymphocyte proliferation by ASCs is reversible in our experimental conditions. That was shown to be the case, because lymphocytes inhibited in the presence of ASCs for $120 \mathrm{~h}$ were able to proliferate again when separated from the ASCs and re-stimulated alone for additional $96 \mathrm{~h}$ (Figure 4A). We next investigated whether $\operatorname{Trp}$ supplementation can restore $\mathrm{T}$-cell proliferation once the inhibitory effect of ASCs has been established and in the remaining presence of the ASCs. To do so, PBMCs were stimulated in the absence or presence of ASCs for $72 \mathrm{~h}$, and proliferation of $\mathrm{T}$ lymphocytes was determined. Cultures were then split into two arms: in one, no additional Trp was added, and in the other one, $200 \mu \mathrm{mol} / \mathrm{L}$ of $\operatorname{Trp}$ was added to the culture medium. This high concentration of Trp was chosen to consider also the potential effects of a very high concomitant accumulation of Kyn. Proliferation of 
A
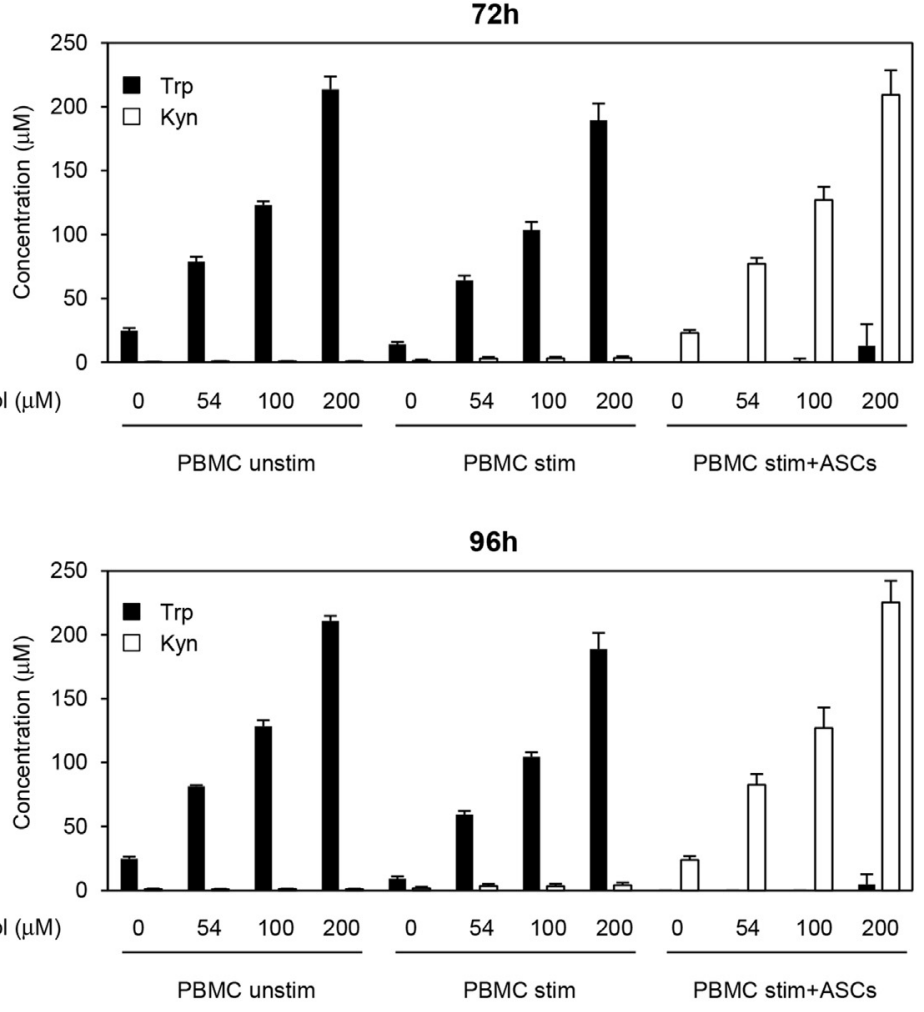

B
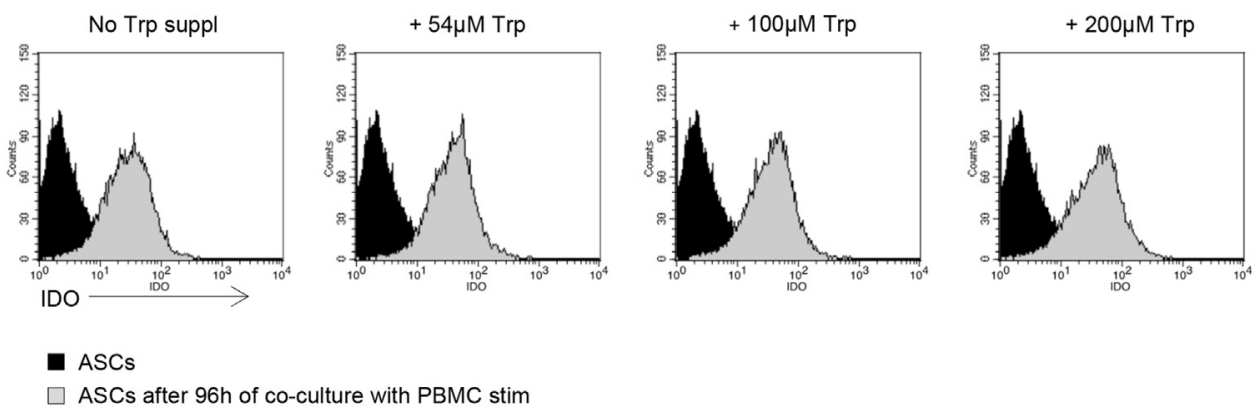

Figure 3. Expression of IDO and levels of Trp and Kyn in supernatants of lymphocyte proliferation assays. (A) Concentration of Trp and Kyn was determined by means of HPLC at different time points. Means and standard deviations of experiments performed with 4 different donors of ASCs and 2 buffy coats, in triplicates, are shown. Black bars indicate Trp; white bars: Kyn. (B) Stimulated PBMCs and ASCs were cultured in transwell conditions, and after $96 \mathrm{~h}$ the expression of IDO by ASCs was determined by means of flow cytometry with the use of a specific antibody against human IDO. Black histogram indicates ASCs; gray histogram, ASCs co-cultured $96 \mathrm{~h}$ with stimulated PBMCs.

T lymphocytes was determined at $120 \mathrm{~h}$ after stimulation (48 $\mathrm{h}$ after Trp addition). As shown in Figure 4B, ASCs actively inhibited T-cell proliferation at $72 \mathrm{~h}$. After $120 \mathrm{~h}$ of stimulation, T lymphocytes alone reached generation 7 (G7), but, when cultured with ASCs, they only reached generation 2 (G2). Importantly, supplementation of Trp at $72 \mathrm{~h}$ partially impaired the inhibitory effect of ASCs and allowed proliferation of $\mathrm{T}$ lymphocytes up to generation 4 (G4). Concentrations of Trp and Kyn were measured at $72 \mathrm{~h}$ and $120 \mathrm{~h}$ by means of HPLC (Figure 4C). At $72 \mathrm{~h}$, complete conversion of Trp into Kyn was found in supernatants from stimulated PBMCs cultured with ASCs (Trp: $0 \mu \mathrm{mol} / \mathrm{L}$; Kyn:
$25.94 \mu \mathrm{mol} / \mathrm{L}$ ), which was concurrent with the inhibition of T-cell proliferation by ASCs. Without additional supplementation of Trp, at $120 \mathrm{~h}$, levels of Trp and Kyn remained similar to those at $72 \mathrm{~h}$. As expected, addition of $200 \mu \mathrm{mol} / \mathrm{L}$ of $\operatorname{Trp}$ at $72 \mathrm{~h}$ increased accordingly the concentration of $\operatorname{Trp}$ detected at $120 \mathrm{~h}$ in unstimulated and stimulated PBMC and augmented proportionally the concentration of Kyn measured in supernatants from stimulated PBMCs cultured with ASCs (Trp: 25.98 $\mu \mathrm{mol} / \mathrm{L}$; Kyn: $241.84 \mu \mathrm{mol} / \mathrm{L})$. Despite this very high accumulation of Kyn, $\mathrm{T}$ lymphocytes proliferated again, indicating that absolute Trp concentration modulates the immunosuppressive properties of 
A

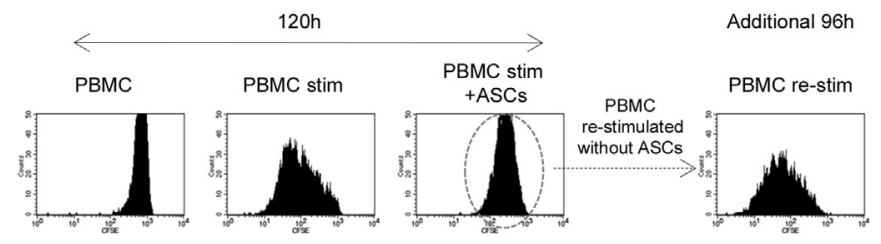

B

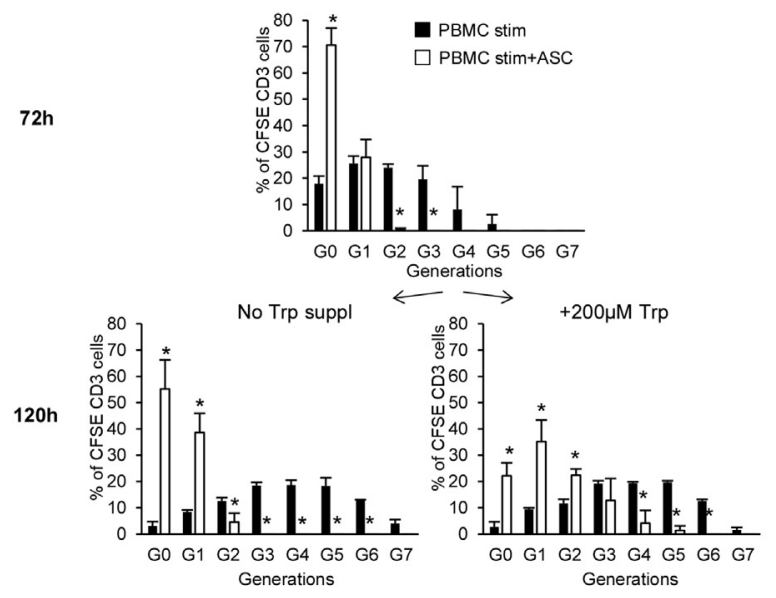

C
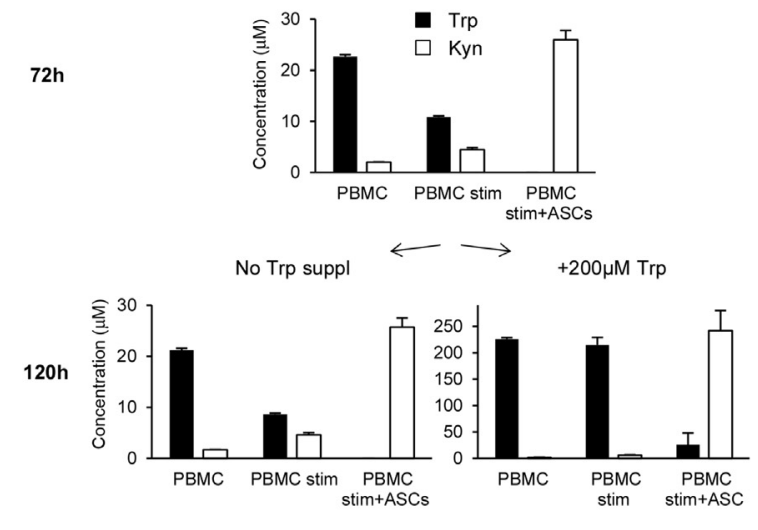

\section{D}
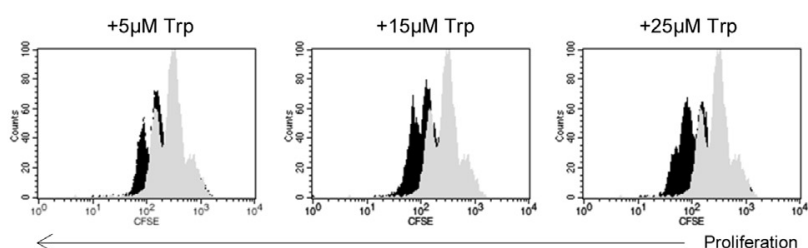

- PBMC stim+ASC (Trp added at $72 \mathrm{~h}$ ) PBMC stim+ASC (no Trp added at $72 \mathrm{~h}$ )

Figure 4. Ongoing ASC-mediated suppression of T-cell proliferation is reverted by Trp supplementation. (A) CFSE-labeled PBMCs were stimulated with anti-CD3/CD2/CD28-coated beads in the absence or presence of ASCs (ratio 1:25, ASCs:PBMCs). Proliferation of the viable CD 3 cells was monitored after $120 \mathrm{~h}$ by means of flow cytometry. Stimulated PBMCs cultured with ASCs were then harvested, spun down, resuspended in fresh medium alone and re-stimulated. Proliferation was monitored after an additional $96 \mathrm{~h}$ by means of flow cytometry. Representative histograms of T-lymphocyte proliferation are shown. (B) PBMCs were stimulated in the absence or presence of ASCs for $72 \mathrm{~h}$, and proliferation of viable T lymphocytes was determined. Cultures were then split into two arms: in one, no additional Trp was added, and in the other, $200 \mu \mathrm{mol} / \mathrm{L}$ of Trp was added to the culture medium. Proliferation of viable T lymphocytes was determined at $120 \mathrm{~h}$ after stimulation ( $48 \mathrm{~h}$ after Trp addition). The percentage of cells per generation was determined with the use of FCSExpress software. Means and standard deviations of the percentage of cells accumulated on each generation are shown. Black bars indicate PBMC stimulated; white bars, PBMC stimulated+ASCs. ${ }^{*} P<0.05$ (Student's $t$-test, PBMCstim versus PBMCstim+ASCs, for each generation). Experiments were performed with 4 donors of ASCs and 2 buffy coats, in triplicates. (C) Concentration of Trp and Kyn was determined by means of HPLC at $72 \mathrm{~h}$ and $120 \mathrm{~h}$. Means and standard deviations of experiments performed with 4 different donors of ASCs and 2 buffy coats, in triplicates, are shown. Black bars indicate Trp; white bars, Kyn. (D) Experiments performed as in B by supplementing the medium with the indicated concentrations of Trp. Representative histogram overlays of T-lymphocyte proliferation are also shown. Black histogram indicates PBMC stimulated+ASCs (Trp added at $72 \mathrm{~h}$ ); gray histogram, PBMC stimulated+ASCs (no Trp added at $72 \mathrm{~h}$ ).

ASCs. Notably, supplementation at $72 \mathrm{~h}$ of as little as $5 \mu \mathrm{mol} / \mathrm{L}$ of $\operatorname{Trp}$ partially supported proliferation of T lymphocytes (Figure 4D).

Trp reversed ASC-mediated immunosuppression of $T$ lymphocytes despite the presence of other antiinflammatory mediators

We next investigated whether other anti-inflammatory mediators were also present in the PBMC:ASC cocultures. To do so, the concentration of IL-10, PGE-2 and HLA-G was determined by means of ELISA in conditioned supernatants at different time points. PGE-2, at $72 \mathrm{~h}$, was detected in supernatants from PBMCs (stimulated or not) and ASCs, indicating that they constitutively express PGE-2. Levels of PGE-2 were markedly increased in the supernatants of stimulated PBMC co-cultured with ASCs (Figure 5A). At $120 \mathrm{~h}, \mathrm{PGE}-2$ concentration increased in stimulated PBMC:ASC co-cultures without any effect of Trp addition (Figure 5B). HLA-G expression, at $72 \mathrm{~h}$, was not detected in unstimulated PBMCs and barely detected in supernatants from ASCs or stimulated PBMCs. Levels of HLA-G slightly increased when 
A
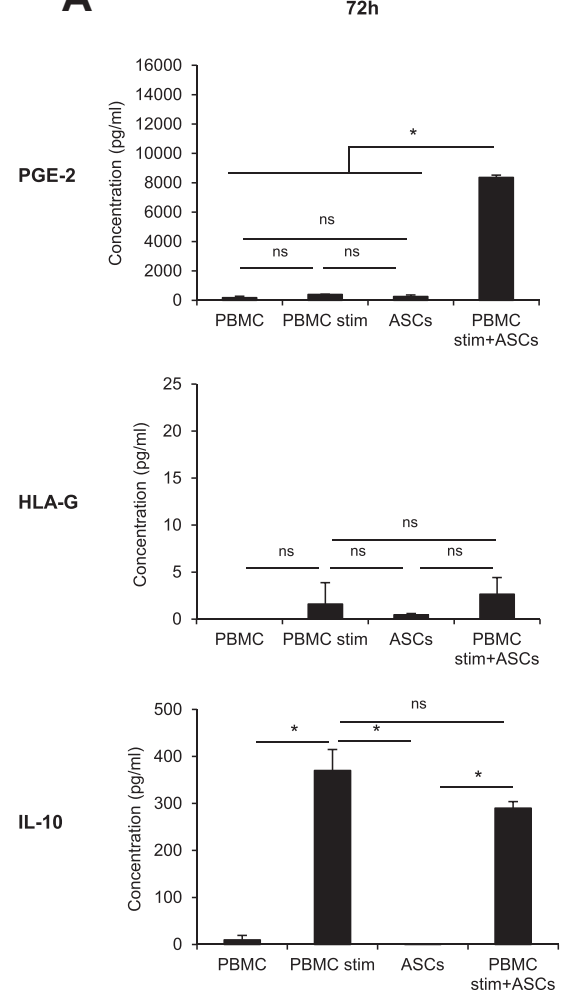

B

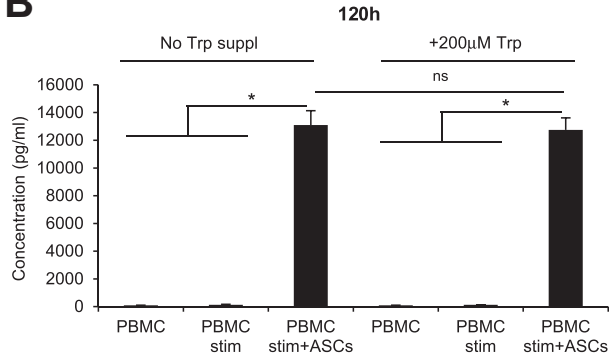

HLA-G

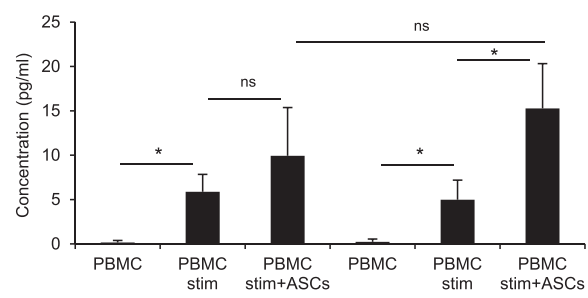

IL-10

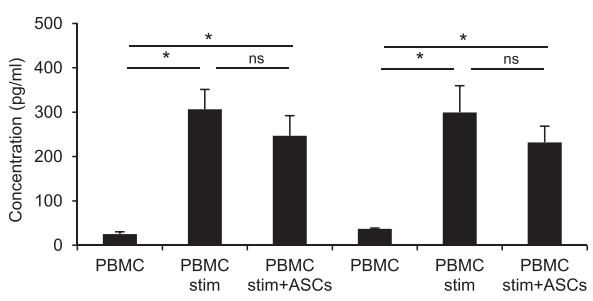

Figure 5. Expression of other anti-inflammatory mediators. Levels of PGE-2, HLA-G and IL-10 were determined in conditioned supernatants at the indicated time points by means of ELISA. Means and standard deviations of 2 experiments performed with 4 donors of ASCs and 2 buffy coats are shown. ${ }^{*} P<0.05$ (Student's $t$-test). ns, Not significant.

stimulated PBMCs were cultured with ASCs (Figure 5A). At $120 \mathrm{~h}$, HLA-G concentration increased in supernatants from stimulated PBMC cultured alone or with ASCs. Supplementation with Trp appeared to increase HLA-G expression at $120 \mathrm{~h}$ in stimulated PBMC:ASC co-cultures (mean: $15.3 \pm$ $5.04 \mathrm{pg} / \mathrm{mL}$ ) compared with co-cultures not supplemented with $\operatorname{Trp}$ (mean: $9.9 \pm 5.4 \mathrm{pg} / \mathrm{mL}$ ), although it was not statistically significant $(P=0.19)$ (Figure 5B). IL-10, at $72 \mathrm{~h}$, was hardly detected in PBMC and ASCs, but it was highly accumulated in supernatants from stimulated PBMC alone or when cultured with ASCs (Figure 5A). At $120 \mathrm{~h}, \mathrm{IL}-10$ levels remained rather stable and were not affected by Trp addition (Figure 5B). Overall, these results indicate that Trp supplementation at $72 \mathrm{~h}$ reversed the established inhibitory effect of ASCs despite the presence in the culture medium of other anti-inflammatory mediators such as PGE-2, HLA-G and IL-10.

\section{Effect of Trp supplementation on viability of $T$ lymphocytes cultured with ASCs}

In addition to the inhibitory effect on $\mathrm{T}$-cell proliferation, we observed that ASCs also reduced the viability of T cells (measured as the CD3+/7AAD-population) after $96 \mathrm{~h}$ of culture from approximately $70 \%$ to $33 \%$
(Figure 6). Addition of Trp had no effects on T lymphocytes alone, but it increased $\mathrm{T}$-cell viability in a dose-dependent manner when cultured with ASCs, although the baseline viability of $70 \%$ could not be regained by Trp supplementation only.

\section{Effect of Kyn addition on T-lymphocyte proliferation}

To further confirm that Trp deprivation rather than Kyn accumulation is the main factor mediating the

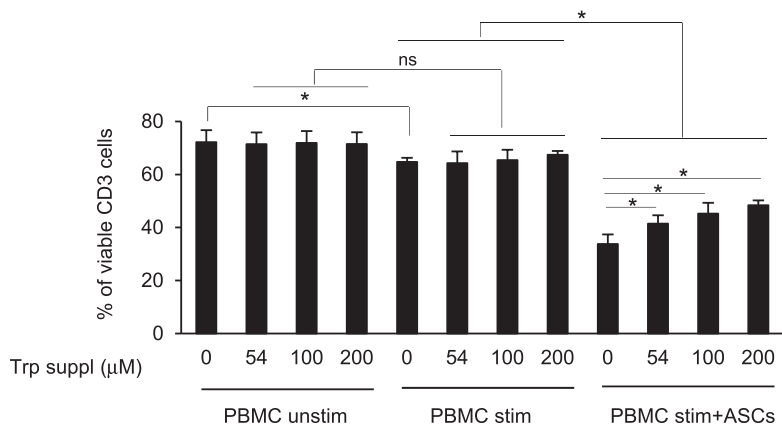

Figure 6. Effect of Trp supplementation on ASC-mediated T-cell death. Means and standard deviations of the percentage of viable $\mathrm{T}$ lymphocytes (CD3 positive/7AAD negative population) at $96 \mathrm{~h}$ are shown. $* P<0.05$ (Student's $t$-test). Experiments were performed with 4 different donors of ASCs and 2 buffy coats, in triplicates. 
immunosuppressive capacity of ASCs, T-lymphocyte proliferation assays were carried out in the presence of increasing concentrations of Kyn (10, 20 and $30 \mu \mathrm{mol} /$ L). These concentrations were selected because, as mentioned above, the concentration of Trp in the medium used in the PBMC proliferation assays is approximately $25 \mu \mathrm{mol} / \mathrm{L}$, which is, therefore, the maximum concentration of Kyn that can be generated in our assays. Consequently, in our experimental settings, if Kyn concentration accounts for the inhibitory effect of ASCs, it must be at concentrations $\leq 25$ $\mu \mathrm{mol} / \mathrm{L}$. PBMCs were stimulated, in the absence or presence of Kyn, and proliferation was determined at $96 \mathrm{~h}$ by means of flow cytometry. As shown in Figure 7A, addition of Kyn inhibited T-cell proliferation in only 1 of 8 buffy coats. To test whether higher concentrations of Kyn could have an inhibitory effect, $\mathrm{T}$-cell proliferation was tested in the presence of 20, 50 and $100 \mu \mathrm{mol} / \mathrm{L}$ of $\mathrm{Kyn}$. Both buffys were inhibited at a concentration of $100 \mu \mathrm{mol} / \mathrm{L}$ (Figure 7B). Therefore, only 1 buffy (B056) was inhibited at a concentration of Kyn that could be generated from the degradation of the Trp existing in our experimental settings. These results indicate that at least in our in vitro experimental conditions, sensitivity of $\mathrm{T}$ lymphocytes to the inhibitory effects of Kyn may vary from donor to donor.

\section{Discussion}

We have previously described that the immunomodulatory properties of human ASCs rely, mainly, on the enzymatic activity of IDO [29]. However, the relative contribution of each arm of the Trp/Kyn balance on the IDO-mediated immunomodulatory mechanism of ASCs has not been studied in detail. In the present study, we investigated this further to show that the capacity of ASCs to inhibit lymphocyte proliferation is primarily mediated by the depletion of Trp levels in the surrounding microenvironment. Hence, Trp supplementation at the time of PBMC:ASC co-culture impaired the inhibitory effect of ASCs, despite the accumulation of Kyn at very high levels $(>200$ $\mu \mathrm{mol} / \mathrm{L})$. The impairment of the immunosuppressive effect of ASCs was dose-dependent and more visible at $72 \mathrm{~h}$ than at $96 \mathrm{~h}$ (Figure 2). Thus, supplementation with $200 \mu \mathrm{mol} / \mathrm{L}$ of Trp almost fully abolished the inhibitory effect of ASCs at $72 \mathrm{~h}$, whereas some inhibition of T-cell proliferation could be detected at $96 \mathrm{~h}$ (Figure 2A). These inhibitory effects at later time points could be explained by the fact that $\operatorname{Trp}$ was virtually fully degraded at $72 \mathrm{~h}$ and $96 \mathrm{~h}$, even at the highest added concentration of $200 \mu \mathrm{mol} / \mathrm{L}$, and therefore the inhibitory capacity of ASCs could have been "switched on" again. Nevertheless, additional inhibitory effects mediated by highly accumulated
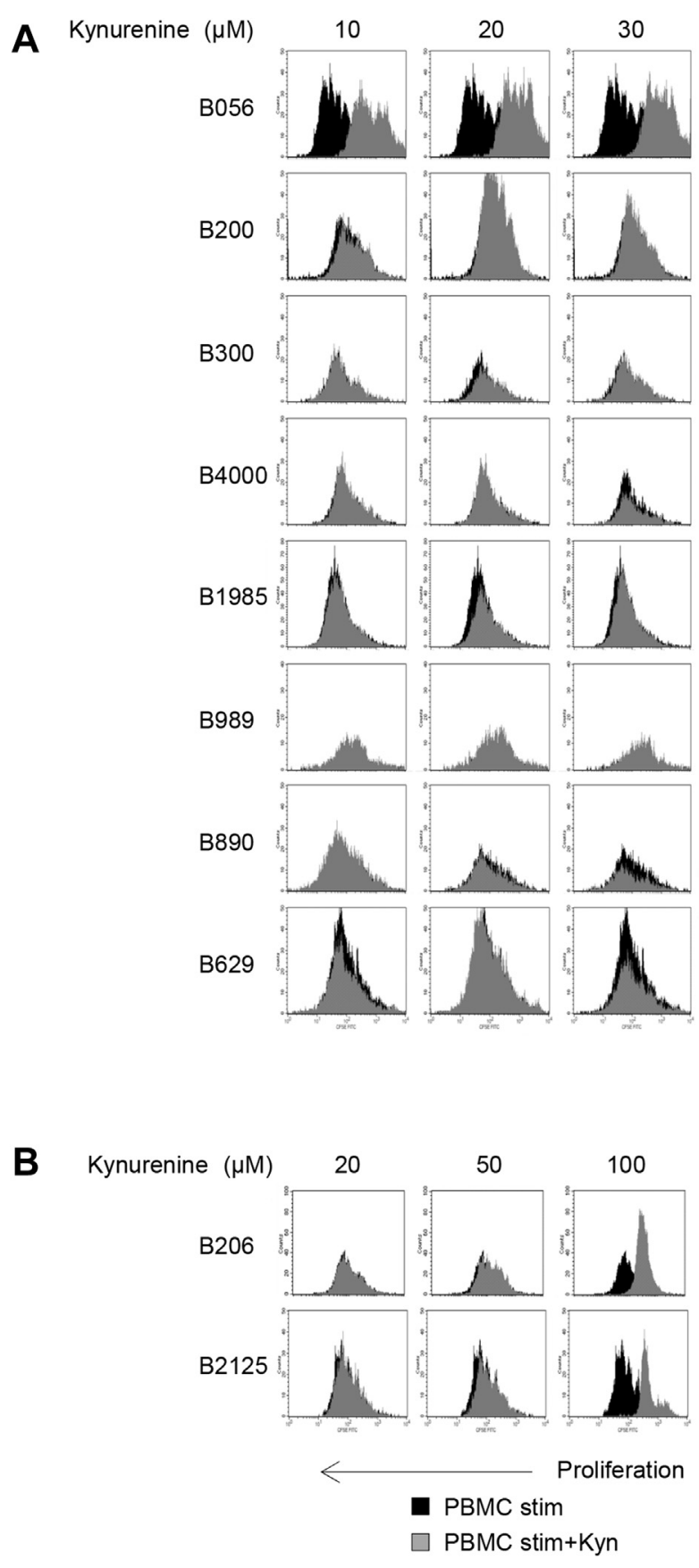

Figure 7. Effect of Kyn addition on proliferation of $\mathrm{T}$ lymphocytes. CFSE-labeled PBMCs from 10 different buffy coats were stimulated with anti-CD3/CD2/CD28-coated beads in the absence or presence of the indicated concentrations of Kyn, and proliferation (CFSE loss) was determined at $96 \mathrm{~h}$ by means of flow cytometry. Black histogram indicates PBMC stimulated; gray histogram, PBMC stimulated + Kyn. Experiments were performed in triplicates. One representative overlay is shown.

Kyn or other factors cannot be ruled out. Importantly, supplementation of Trp after $72 \mathrm{~h}$ of co-culture, once T-cell proliferation was already blocked by ASCs, restored $\mathrm{T}$-cell proliferation, indicating that the inhibitory effects of ASCs on T-cell proliferation are reversible and can be modulated by the absolute level 
of Trp concentration. Interestingly, the effects of Trp supplementation were observed despite the presence in the medium of high Kyn and other anti-inflammatory mediators such as PGE-2, HLA-G and IL-10 (Figure 5) that have also been implicated in the mechanism of immunomodulation by MSCs [12].

Thus far, non-conclusive and occasionally contradictory results have been reported when inhibiting any of these soluble immunosuppressive factors and their relative contribution to the immunomodulatory properties of MSCs varies between different studies $[32,33]$. We observed that PGE-2 levels were markedly increased when stimulated PBMCs and ASCs were cultured together (Figure 5), which was probably caused by the upregulated expression of PGE-2 by ASCs activated through inflammatory cytokines released by stimulated PBMC (mainly TNF- $\alpha$ ), as reported previously by others [34,35]. Despite the high accumulation of PGE-2 observed in our PBMC:ASC co-cultures and the reported effects of PGE-2 as a key mediator of the immunomodulatory properties of MSCs [36,37], Trp supplementation impaired the capacity of ASCs to inhibit lymphocyte proliferation, indicating that in our experimental conditions, depletion of Trp plays a more important role than PGE-2 in mediating the capacity of ASCs to suppress $\mathrm{T}$-cell proliferation. This is in agreement with our previous results when addition of indomethacin, an inhibitor of PGE-2 production, did not significantly block the capacity of ASCs to inhibit lymphocyte proliferation [29]. These inconsistent results might be related to differences in the experimental conditions between studies. For instance, the use of PBMCs versus purified $\mathrm{T}$ cells or the method of activation of these cells (anti-CD3/CD2/CD28 versus mixed lymphocyte reaction) might be relevant. In addition, IL-10 production was found to be barely detectable in ASCs and highly upregulated in stimulated PBMCs (Figure 5). Co-culture of PBMCs with ASCs did not significantly affect its expression, indicating that IL-10 is produced by activated PBMCs and suggesting that these concentrations of IL-10 do not have important immunosuppressive effects in our experimental conditions. On the other hand, HLA-G was found to be expressed by ASCs, although to lower levels compared with stimulated PBMCs. Interestingly, we observed that the expression of HLA-G appeared to be increased in PBMC:ASC co-cultures when Trp was supplemented (Figure 5B). Although it was not statistically significant compared with the same conditions without Trp addition, this observation may suggest that HLA-G expression might be regulated by Trp metabolism, as previously reported [38]. Nevertheless, despite the described role of HLA-G in the immunomodulatory effects of MSCs
$[39,40]$, Trp addition impaired the immunomodulatory properties of ASCs, indicating that HLA-G, as PGE-2, does not appear to be a key mediator of the inhibitory effects of ASCs in our in vitro settings. Overall, our results suggest that in our experimental conditions, there is an apparent hierarchy among different immunomodulators used by MSCs, being depletion of Trp the major mechanism used by ASCs to inhibit lymphocyte proliferation.

To further clarify the role of Kyn in the inhibition of T-lymphocyte proliferation, we studied the proliferation of $\mathrm{T}$ lymphocytes in the presence of increasing concentrations of Kyn. Of 10 buffys studied, 3 were inhibited by Kyn addition but at different concentrations. Two were inhibited at a concentration of $100 \mu \mathrm{mol} / \mathrm{L}$, which is far above the maximum concentration of Kyn that can be generated from the Trp present in RPMI supplemented with $10 \%$ FBS (maximum of $25 \mu \mathrm{mol} / \mathrm{L}$ ). Only buffy B056 was inhibited at concentrations of Kyn $(10-30 \mu \mathrm{mol} / \mathrm{L})$ that can be generated by ASCs in our experimental settings. Therefore, these results suggest that at least in our in vitro experimental conditions, Kyn accumulation is not the main driver of ASC-mediated inhibition of $\mathrm{T}$-cell proliferation because concentrations of Kyn $\leq 25 \mu \mathrm{mol} / \mathrm{L}$ do not appear to interfere with $\mathrm{T}$ proliferation of most PBMC donors. Moreover, these results suggest that the susceptibility of $\mathrm{T}$ cells to the inhibitory/toxic effect of Kyn might be donor-dependent. This could explain the inconsistency of the Kyn effects that we report here compared with those reported previously [20-23,29]. In agreement with previous studies $[11,41]$, we observed that ASCs increased cell death of T lymphocytes. The induction of T-cell death by ASCs was partially inhibited by Trp supplementation (Figure 6), indicating that other factors, including Kyn accumulation [20], might play a role.

Our results show that Trp depletion by IDO activity is the predominant mediator of the immunomodulatory properties of ASCs in our in vitro settings. However, it must be elucidated whether IDO activity plays a similar predominant role in the therapeutic effects of human MSCs in patients or in experimental animal models of inflammatory diseases (often in mice and rats). Recently, it has been described that the mechanism mediating the immunosuppressive effects of MSCs is species-dependent [15]. Mouse, rat, hamster and rabbit MSCs use inducible nitric oxide synthase, whereas human, monkey and pig use IDO. On the basis of these differences, Su et al. [15] raised the interesting question on to what extent efficacy preclinical studies in mice with the use of human MSCs are relevant for human disease [15]. The fact that mouse MSCs do not use IDO does not preclude that human MSCs 
could express IDO after administration into mice and exert their therapeutic effects, at least in part, through the local depletion of Trp. In fact, inhibition or disruption of IDO activity has been described to aggravate collagen-induced arthritis and colitis in mice [42-45], showing that IDO is an important regulator of immune responses in mice. Further research in experimental animal models of inflammation with the use of IDO-deficient human MSCs or pharmacological inhibitors of IDO along with the cells will be very valuable to clarify the use of IDO activity by human MSCs in vivo and therefore the mechanistic relevance for human disease of the use of current animal models.

Our results also show that the inhibitory effects of ASCs on proliferating $T$ cells are reversible and mainly mediated through the local metabolic control of Trp access, implying that the immunomodulatory effects of MSCs could be temporary. The hope of treating chronic inflammatory diseases with MSCs is that they would reach a sustained modulation of the chronically imbalanced immune response, typical of these diseases, resulting in a durable therapeutic effect. Although MSCs have been proven to be efficacious in experimental animal models of inflammation [46-50] through a "hit-and-run" mechanism, further investigation is needed to positively establish that cells that use reversible/transient mechanisms and have short persistence in vivo can really achieve the desired lasting therapeutic effects in clinical settings.

\section{Acknowledgments}

We thank Debjani Roy (TiGenix NV) for critical reading of the manuscript. This project received funding from the Spanish Ministry of Economy and the European Union's Seventh Programme for research, technological development and demonstration under grant agreement no. 279174 to TiGenix.

Disclosure of interests: The authors are full-time employees of TiGenix.

\section{References}

[1] Di Nicola M, Carlo-Stella C, Magni M, Milanesi M, Longoni PD, Matteucci P, et al. Human bone marrow stromal cells suppress T-lymphocyte proliferation induced by cellular or nonspecific mitogenic stimuli. Blood 2002;99:3838-43.

[2] Krampera M, Glennie S, Dyson J, Scott D, Laylor R, Simpson E, et al. Bone marrow mesenchymal stem cells inhibit the response of naive and memory antigen-specific $\mathrm{T}$ cells to their cognate peptide. Blood 2003;101:3722-9.

[3] Ghannam S, Pène J, Torcy-Moquet G, Jorgensen C, Yssel H. Mesenchymal stem cells inhibit human Th17 cell differentiation and function and induce a $\mathrm{T}$ regulatory cell phenotype. J Immunol 2010;185:302-12.
[4] Prigione I, Benvenuto F, Bocca P, Battistini L, Uccelli A, Pistoia V. Reciprocal interactions between human mesenchymal stem cells and gammadelta $\mathrm{T}$ cells or invariant natural killer T cells. Stem Cells 2009;27:693-702.

[5] Corcione A, Benvenuto F, Ferretti E, Giunti D, Cappiello V, Cazzanti F, et al. Human mesenchymal stem cells modulate B-cell functions. Blood 2006;107:367-72.

[6] Raffaghello L, Bianchi G, Bertolotto M, Montecucco F, Busca A, Dallegri F, et al. Human mesenchymal stem cells inhibit neutrophil apoptosis: a model for neutrophil preservation in the bone marrow niche. Stem Cells 2008;26:151-62.

[7] Delarosa O, Sánchez-Correa B, Morgado S, Ramírez C, Del Río B, Menta R, et al. Human adipose-derived stem cells impair natural killer cell function and exhibit low susceptibility to natural killer-mediated lysis. Stem Cells Dev 2012;21: 1333-43.

[8] Friedenstein AJ, Gorskaja JF, Kulagina NN. Fibroblast precursors in normal and irradiated mouse hematopoietic organs. Exp Hematol 1976;4:267-74.

[9] Zuk PA, Zhu M, Ashjian P, De Ugarte DA, Huang JI, Mizuno $\mathrm{H}$, et al. Human adipose tissue is a source of multipotent stem cells. Mol Biol Cell 2002;13:4279-95.

[10] Liotta F, Angeli R, Cosmi L, Filì L, Manuelli C, Frosali F, et al. Toll-like receptors 3 and 4 are expressed by human bone marrow-derived mesenchymal stem cells and can inhibit their T-cell modulatory activity by impairing Notch signaling. Stem Cells 2008;26:279-89.

[11] Akiyama K, Chen C, Wang D, Xu X, Qu C, Takayoshi Y, et al. Mesenchymal stem cell induced immunoregulation involves Fas-ligand-/Fas-mediated $\mathrm{T}$ cell apoptosis. Cell Stem Cell 2012;10:1-12.

[12] Doorn J, Moll G, Le Blanc K, van Blitterswijk C, de Boer J. Therapeutic applications of mesenchymal stromal cells: paracrine effects and potential improvements. Tissue Eng Part B Rev 2012;18:101-15.

[13] Meisel R, Zibert A, Laryea M, Göbel U, Däubener W, Dillo D. Human bone marrow stromal cells inhibit allogeneic T-cell responses by indoleamine 2,3-dioxygenase-mediated tryptophan degradation. Blood 2004;103:4619-21.

[14] Ren G, Su J, Zhang L, Zhao X, Ling W, L'huillie A, et al. Species variation in the mechanisms of mesenchymal stem cell-mediated immunosuppression. Stem Cells 2009;27: 1954-62.

[15] Su J, Chen X, Huang Y, Li W, Li J, Cao K, et al. Phylogenetic distinction of iNOS and IDO function in mesenchymal stem cell-mediated immunosuppression in mammalian species. Cell Death Differ 2014;21:388-96.

[16] Krampera M, Cosmi L, Angeli R, Pasini A, Liotta F, Andreini A, et al. Role for interferon-gamma in the immunomodulatory activity of human bone marrow mesenchymal stem cells. Stem Cells 2006;24:386-98.

[17] Prasanna SJ, Gopalakrishnan D, Shankar SR, Vasandan AB. Pro-inflammatory cytokines, IFNgamma and TNFalpha, influence immune properties of human bone marrow and Wharton jelly mesenchymal stem cells differentially. PLoS One 2010;5:e9016.

[18] Munn DH, Mellor AL. Indoleamine 2,3 dioxygenase and metabolic control of immune responses. Trends Immunol 2013;34:137-43.

[19] Mellor AL, Munn DH. Tryptophan catabolism and regulation of adaptive immunity. J Immunol 2003;170:5809-13.

[20] Fallarino F, Grohmann U, Vacca C, Bianchi R, Orabona C, Spreca A, et al. T cell apoptosis by tryptophan catabolism. Cell Death Differ 2002;9:1069-77.

[21] Frumento G, Rotondo R, Tonetti M, Damonte G, Benatti U, Ferrara GB. Tryptophan-derived catabolites are responsible for inhibition of $\mathrm{T}$ and natural killer cell 
proliferation induced by indoleamine 2,3-dioxygenase. J Exp Med 2002;196:459-68.

[22] Terness P, Bauer TM, Röse L, Dufter C, Watzlik A, Simon $\mathrm{H}$, et al. Inhibition of allogeneic $\mathrm{T}$ cell proliferation by indoleamine 2,3-dioxygenase-expressing dendritic cells: mediation of suppression by tryptophan metabolites. J Exp Med 2002;196:447-57.

[23] Weber WP, Feder-Mengus C, Chiarugi A, Rosenthal R, Reschner A, Schumacher R, et al. Differential effects of the tryptophan metabolite 3-hydroxyanthranilic acid on the proliferation of human CD8 $+\mathrm{T}$ cells induced by TCR triggering or homeostatic cytokines. Eur J Immunol 2006;36: 296-304.

[24] Mezrich JD, Fechner JH, Zhang X, Johnson BP, Burlingham WJ, Bradfield CA. An interaction between kynurenine and the aryl hydrocarbon receptor can generate regulatory T cells. J Immunol 2010;185:3190-8.

[25] Fallarino F, Grohmann U, You S, McGrath BC, Cavener DR, Vacca C, et al. The combined effects of tryptophan starvation and tryptophan catabolites down-regulate $\mathrm{T}$ cell receptor zeta-chain and induce a regulatory phenotype in naive T cells. J Immunol 2006;176:6752-61.

[26] Munn DH, Sharma MD, Baban B, Harding HP, Zhang Y, Ron D, et al. GCN2 kinase in T cells mediates proliferative arrest and anergy induction in response to indoleamine 2,3dioxygenase. Immunity 2005;22:633-42.

[27] Metz R, Rust S, Duhadaway JB, Mautino MR, Munn DH, Vahanian NN, et al. IDO inhibits a tryptophan sufficiency signal that stimulates mTOR: a novel IDO effector pathway targeted by D-1-methyl-tryptophan. Oncoimmunology 2012;1:1460-8.

[28] Pallotta MT, Orabona C, Volpi C, Vacca C, Belladonna ML, Bianchi $\mathrm{R}$, et al. Indoleamine 2,3-dioxygenase is a signaling protein in long-term tolerance by dendritic cells. Nat Immunol 2011;12:870-8.

[29] DelaRosa O, Lombardo E, Beraza A, Mancheño-Corvo P, Ramirez C, Menta R, et al. Requirement of IFN-gammamediated indoleamine 2,3-dioxygenase expression in the modulation of lymphocyte proliferation by human adiposederived stem cells. Tissue Eng Part A 2009;15:2795-806.

[30] Ryan JM, Barry F, Murphy JM, Mahon BP. Interferongamma does not break, but promotes the immunosuppressive capacity of adult human mesenchymal stem cells. Clin Exp Immunol 2007;149:353-63.

[31] Dominici M, Le Blanc K, Mueller I, Slaper-Cortenbach I, Marini F, Krause D, et al. Minimal criteria for defining multipotent mesenchymal stromal cells: the International Society for Cellular Therapy position statement. Cytotherapy 2006;8:315-7.

[32] Uccelli A, Moretta L, Pistoia V. Mesenchymal stem cells in health and disease. Nat Rev Immunol 2008;8:726-36.

[33] Nauta AJ, Fibbe WE. Immunomodulatory properties of mesenchymal stromal cells. Blood 2007;110:3499-506.

[34] Yañez R, Oviedo A, Aldea M, Bueren JA, Lamana ML. Prostaglandin E2 plays a key role in the immunosuppressive properties of adipose and bone marrow tissue-derived mesenchymal stromal cells. Exp Cell Res 2010;316:3109-23.

[35] Hegyi B, Kudlik G, Monostori E, Uher F. Activated T-cells and pro-inflammatory cytokines differentially regulate prostaglandin E2 secretion by mesenchymal stem cells. Biochem Biophys Res Commun 2012;419:215-20.
[36] Yañez R, Lamana ML, García-Castro J, Colmenero I, Ramírez M, Bueren JA. Adipose tissue-derived mesenchymal stem cells have in vivo immunosuppressive properties applicable for the control of the graft-versus-host disease. Stem Cells 2006;24:2582-91.

[37] Cui L, Yin S, Liu W, Li N, Zhang W, Cao Y. Expanded adipose-derived stem cells suppress mixed lymphocyte reaction by secretion of prostaglandin E2. Tissue Eng 2007; 13: 1185-95.

[38] López AS, Alegre E, LeMaoult J, Carosella E, González A. Regulatory role of tryptophan degradation pathway in HLA$\mathrm{G}$ expression by human monocyte-derived dendritic cells. Mol Immunol 2006;43:2151-60.

[39] Nasef A, Mathieu N, Chapel A, Frick J, François S, Mazurier C, et al. Immunosuppressive effects of mesenchymal stem cells: involvement of HLA-G. Transplantation 2007;84:231-7.

[40] Selmani Z, Naji A, Gaiffe E, Obert L, Tiberghien P, RouasFreiss N, et al. HLA-G is a crucial immunosuppressive molecule secreted by adult human mesenchymal stem cells. Transplantation 2009;87(Suppl 9):S62-6.

[41] Plumas J, Chaperot L, Richard MJ, Molens JP, Bensa JC, Favrot MC. Mesenchymal stem cells induce apoptosis of activated T cells. Leukemia 2005;19:1597-604.

[42] Szántó S, Koreny T, Mikecz K, Glant TT, Szekanecz Z, Varga J. Inhibition of indoleamine 2,3-dioxygenase-mediated tryptophan catabolism accelerates collagen-induced arthritis in mice. Arthritis Res Ther 2007;9:R50.

[43] Hoshino S, Kurishima A, Inaba M, Ando Y, Fukui T, Uchida K, et al. Amelioration of 2,4,6-trinitrobenzene sulfonic acid-induced colitis in mice by immunoregulatory dendritic cells. J Gastroenterol 2011;46:1368-81.

[44] Hirata A, Ohtaki H, Hoshi M, Hatano Y, Tomita H, et al. IDO1 plays an immunosuppressive role in 2,4,6-trinitrobenzene sulfate-induced colitis in mice. J Immunol 2013; 191:3057-64.

[45] Lee J, Lee J, Park MK, Lim MA, Park EM, Kim EK, et al. Interferon gamma suppresses collagen-induced arthritis by regulation of Th17 through the induction of indoleamine-2, 3-deoxygenase. PLoS One 2013;8:e60900.

[46] Le Blanc K, Rasmusson I, Sundberg B, Götherström C, Hassan M, Uzunel M, et al. Treatment of severe acute graftversus-host disease with third party haploidentical mesenchymal stem cells. Lancet 2004;363:1439-41.

[47] Zappia E, Casazza S, Pedemonte E, Benvenuto F, Bonanni I, Gerdoni E, et al. Mesenchymal stem cells ameliorate experimental autoimmune encephalomyelitis inducing $\mathrm{T}$-cell anergy. Blood 2005;106:1755-61.

[48] Németh K, Leelahavanichkul A, Yuen PS, Mayer B, Parmelee A, Doi K, et al. Bone marrow stromal cells attenuate sepsis via prostaglandin $\mathrm{E}(2)$-dependent reprogramming of host macrophages to increase their interleukin-10 production. Nat Med 2009;15:42-9. Erratum in: Nat Med 2009;15:462.

[49] González MA, Gonzalez-Rey E, Rico L, Büscher D, Delgado M. Treatment of experimental arthritis by inducing immune tolerance with human adipose-derived mesenchymal stem cells. Arthritis Rheum 2009;60:1006-19.

[50] Gonzalez-Rey E, Anderson P, González MA, Rico L, Büscher D, Delgado M. Human adult stem cells derived from adipose tissue protect against experimental colitis and sepsis. Gut 2009;58:929-39. 